\title{
Easy Determination of Radiation Absorption in Brain Tissue from Mobile Phones Using Finite Element Method
}

\author{
Abubakar Yakubu'1, Zulkifly Abbas ${ }^{2}$, Zainab Yunusa ${ }^{3}$ \\ ${ }^{1}$ Department of Physics, Kebbi State University of Science and Technology, Aliero, Nigeria \\ ${ }^{2}$ Department of Physics, Universiti Putra Malaysia, Selangor, Malaysia \\ ${ }^{3}$ Department of Mechatronics, Bayero University, Kano, Nigeria \\ Email: a.yaks@ksusta.edu,ngabulect73@yahoo.com
}

How to cite this paper: Yakubu, A., Abbas, Z. and Yunusa, Z. (2019) Easy Determination of Radiation Absorption in Brain Tissue from Mobile Phones Using Finite Element Method. Open Journal of Biophysics, 9, 147-154.

https://doi.org/10.4236/ojbiphy.2019.93011

Received: August 25, 2018

Accepted: May 18, 2019

Published: May 21, 2019

Copyright $\odot 2019$ by author(s) and Scientific Research Publishing Inc. This work is licensed under the Creative Commons Attribution International License (CC BY 4.0).

http://creativecommons.org/licenses/by/4.0/

\begin{abstract}
Brain tissue plays a significant role in both cognitive and psychomotor behavior of humans. However, their interaction with radiation emanating from hand held mobile devices is still not fully understood. This research was aimed at investigating radiation absorption in brain tissue. Bovine brain tissues ranging from lesser than 1 year to greater than 10 years of age were bought from a specialty store (Sigma-Aldrich). The tissues were used within $72 \mathrm{~h}$ of extraction for ex vivo brain experiments. The brain tissue was stored at $6^{\circ} \mathrm{C}$ and then $16^{\circ} \mathrm{C}$ for $24 \mathrm{~h}$ in the MRI room to reach thermal equilibrium before any experiments were undertaken. The averages for the dielectric constant were measured from 1 - $4 \mathrm{GHz}$ using open ended coaxial probe (OECP) (85,070E; Agilent Technologies). The results obtained for the dielectric properties were then used as raw data in the numerical computation and simulation of the radiation absorption by the brain tissues for both adolescent and adults bovine brain tissue using finite element method (FEM). The measured dielectric constants varied for the different brain tissue from 54.39 to 39.29. Analysis showed that adolescents tissue absorbed more radiation than adults from mobile phoneradiation which is due to the higher dielectric property of adolescent brain tissue. The results obtained can be applied to human brain tissue since bovine shares the same compositional properties with humans.
\end{abstract}

\section{Keywords}

Bovine Brain Tissue, Dielectric Constant, Mobile Phones, Coaxial Probe, Finite Element Method 


\section{Introduction}

Current usage of mobile telephones has plunged the industry into critical thinking of how to curb the menace of electromagnetic interference (EMI) pollution arising from the ever growing number of the telecommunication users via mobile telephones, local area networks, wide area networks and radar systems [1]. Electromagnetic fields are part of our daily life which includes, mobile phones, radio, Wi-Fi, etc. This research work is focused primarily on mobile telephony. The waves associated with mobile phones are numerous and also vary depending on the platform of operation such as Wi-Fi, Bluetooth, GSM antennas, 2G, UMTS or $3 \mathrm{G}$, power grids. All the mentioned radiations are possible potentials to high health hazards. This research determines radiation absorption by brain tissue from brain tissue measurements in accordance with institutional and regulatory requirements.

It is reported in [2] that the Council of Europe recommended limitations on the use of mobile phones and internet access in all schools across the continent to protect young children from potentially harmful radiation. In [3], their study found that low-dose ionizing radiation exposure affects cognitive skills in exposed children later in life. It is reported that high doses of ionizing radiation to the head (20 - $50 \mathrm{~Gy})$ lead to severe learning and memory impairment which is characteristic for Alzheimer's at old age [4] [5]. It is reported in [6] that $2.4 \mathrm{GHz}$ $\mathrm{Wi}$-Fi radiation emitted from wireless internet equipment altered the expression of two of five miRNAs.

Humans are exposed to an increasing amount of non-ionizing electromagnetic radiation emitted from sources such as cell phones, power transmission lines, radars, and medical equipment, causing public health concerns [7]. Safety standards defining upper limits for the specific absorption rates (SARs) were thus established to serve as guidelines for equipment manufacturers in various fields [8]. The Federal Communications Commission (FCC) in the United States has set an SAR limit of $1.6 \mathrm{~W} / \mathrm{kg}$ averaged over $1 \mathrm{~g}$ of tissue for partial-body exposure, whereas the Council of the European Union allows a limit of $2.0 \mathrm{~W} / \mathrm{kg}$ averaged over $10 \mathrm{~g}$ of tissue [9] [10]. Extensive cell phone use is known to present the highest radio frequency (RF) exposure to the general public [11].

Cell phone radiation exposure generally depends on emitted RF power, but to some extent this radiation depends on other parameters such as RF, antenna position relative to the head, duration of exposure and the material properties of the absorbing tissue. The maximum RF power emitted from handsets available today varies as mobile technology has evolved through generations. Brain tissue has a variable iron concentration that causes magnetic susceptibility heterogeneity induced contrast in EM imaging [12]. Moreover, such difference in magnetic and electrical properties of the brain tissue varies with age, causing variations in both EM imaging and absorption. Due to the explosive growth of the telecommunication industry, radiation emission doses are on the increase. Therefore, it is important to understand the relationship between electromagnetic fields radi- 
ation absorption with brain tissue.

In the light of the above, this research is focused on investigating the effects of the cell phone radiation on human brain and does not investigate any medical or physiological, effects of cell phone radiation on humans. The question pertinent to ask is, what are the risks of mobile phones on human health? For possible answers to this question, there is need to practically measure and analyze the amount of radiation absorbed by brain tissue during mobile telephony conversation. Depicted in Figure 1 are the possible effects of ionizing radiation to the brain.

\section{Methodology}

The purchased human brain tissue is placed inside a sample holder after initial preservation for dielectric measurement. The tissue for the less than 1 year was first measured and repeated for about five times. The same experimental procedure is repeated for the other brain tissues. The average of the results were then recorded further use.

\subsection{Procedure}

After standardize calibration of the open ended coaxial sensor, the probe is place in contact with the tissue avoiding any air gap between the probe and the tissue. The results obtained for the measurements are analysed for the dielectric constant and loss factor. Figure 2(a) \& Figure 2(b) are typical bovine brain tissue after extraction and OECP set-up for measurement of dielectric properties of the brain. All measurements were carried out at room temperature.

\subsection{Simulation}

The human brain is modelled to transit through a microstrip antenna using the

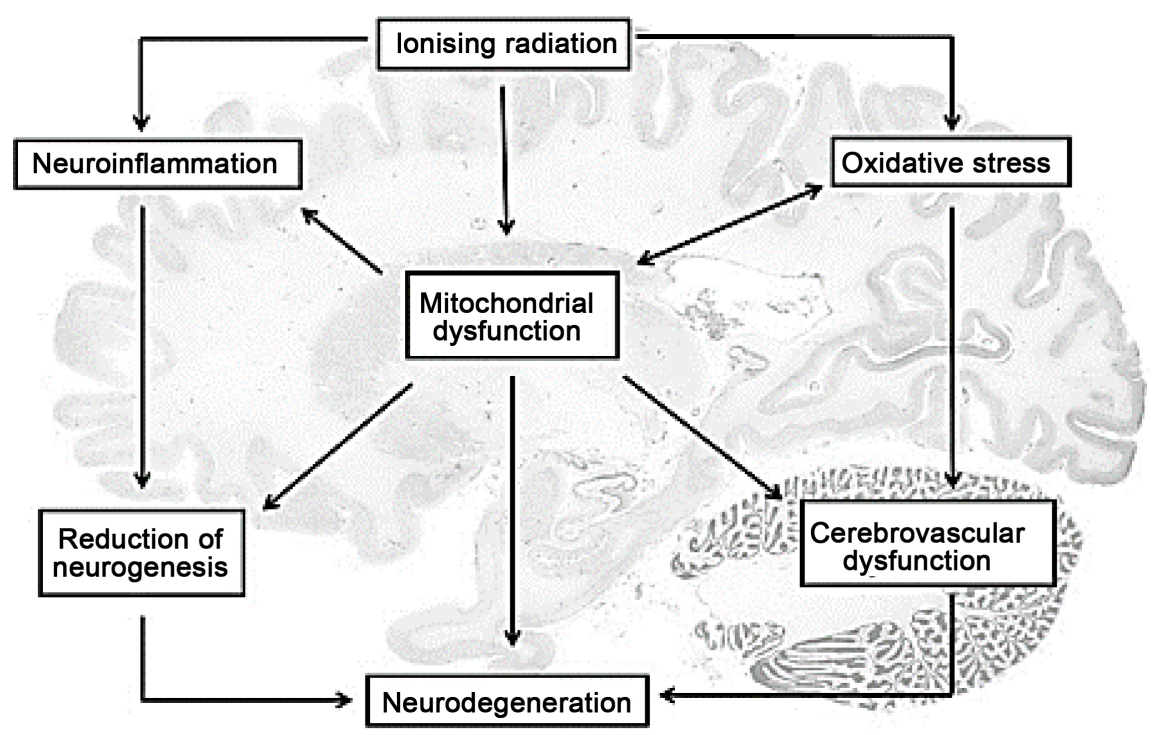

Figure 1. Possible neurodegeneration of the brain after exposure to ionizing radiation [13]. 


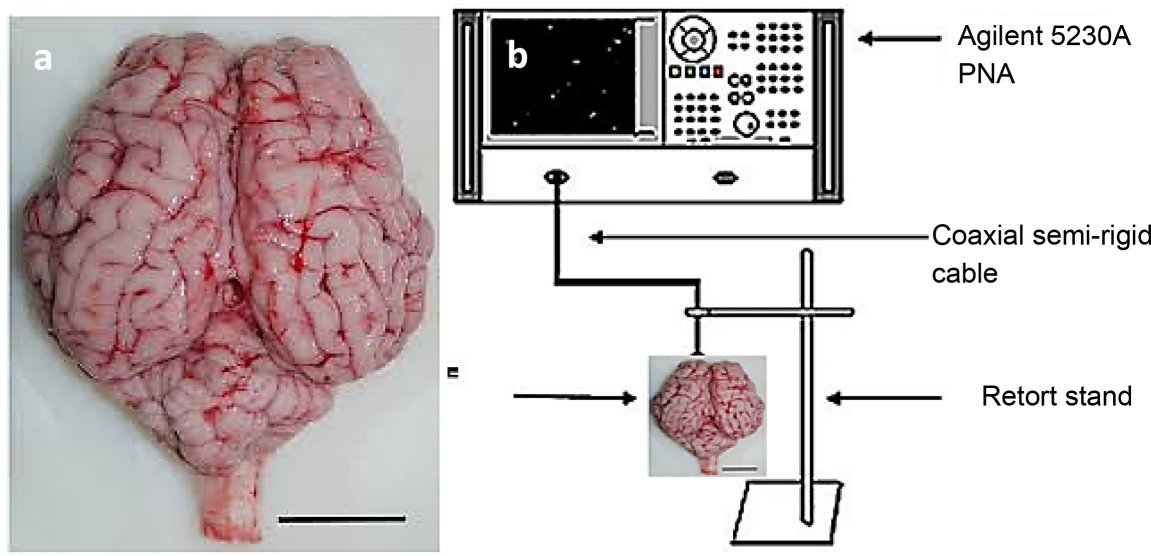

Figure 2. Typical bovine Brain. (a) Typical adolescent bovine brain tissue (b) Measurement set-up.

finite element method (FEM) COMSOL Software V4.5b, America. FEM imaging offers sufficient spatial and temporal resolution to characterize the hot spots from absorbed cell phone radiation in both aqueous media and biological tissues. The microstrip antenna is commercially available which are machined according to specification. In this work, the tissue was excited with RF radiation power of $2500 \mathrm{~mW}$ power.

A typical microstrip has a flat conducting walls anchored with SMA at the ends. In the simulating the tissue placed on the microstrip, the walls of the microstrip was approximated as perfect conductors [14]. Figure 3 is a meshed human brain tissue simulated using the finite element method version $4.5 \mathrm{~b}$. The mesh brain tissue is assumed to be a perfect conductor at the boundaries of the microstrip. They are perfect conductor due to the salt like and moist nature of the brain.

\section{Results}

The variation in dielectric constant for all bovine brain tissues between $1 \mathrm{GHz}$ and $4 \mathrm{GHz}$ using OECP is shown in Figure 4. Careful observation and computation showed that the average values for the dielectric constant are 54.39, 48.14, 44.62 and 39.21 for $<1$ yr, 5 yrs, 10 yrs and $>10$ yrs old bovine brain tissues, respectively.

Further analysis clearly shows that, the tissues of the young bovine possess higher dielectric constant at frequency of $2.4 \mathrm{GHz}$ which is mostly associated with all Wi-Fi (Mobile phones).

The high dielectric constant of the lesser than 1 year tissue could be attributed to higher iron content of the brain tissue. Results also showed that dielectric constant decreases as frequency increases for all brain tissue. This behavior is in accordance with the theory of [15] who stated that, for semi-liquid dielectric medium, as frequency increases, the dielectric constant decreases. Based on Pozar theory, it is concluded that our measurement and findings conforms to law.

The radiation imaging for the different categories of bovine brain are shown in Figure 5. The yellow and blue color represents the intensity of the electric 


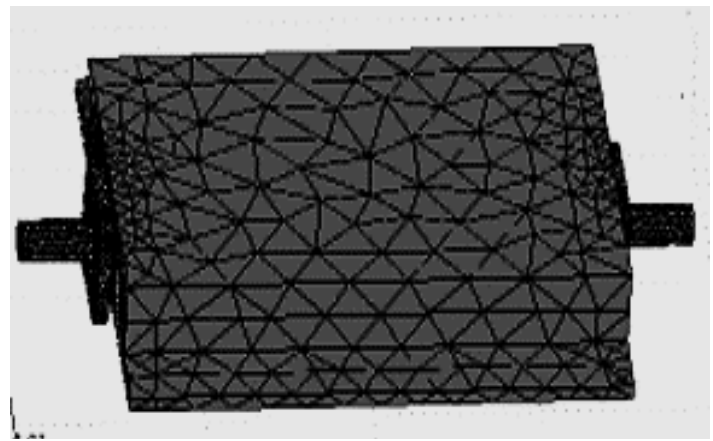

Figure 3. Meshed humanbrain tissue.

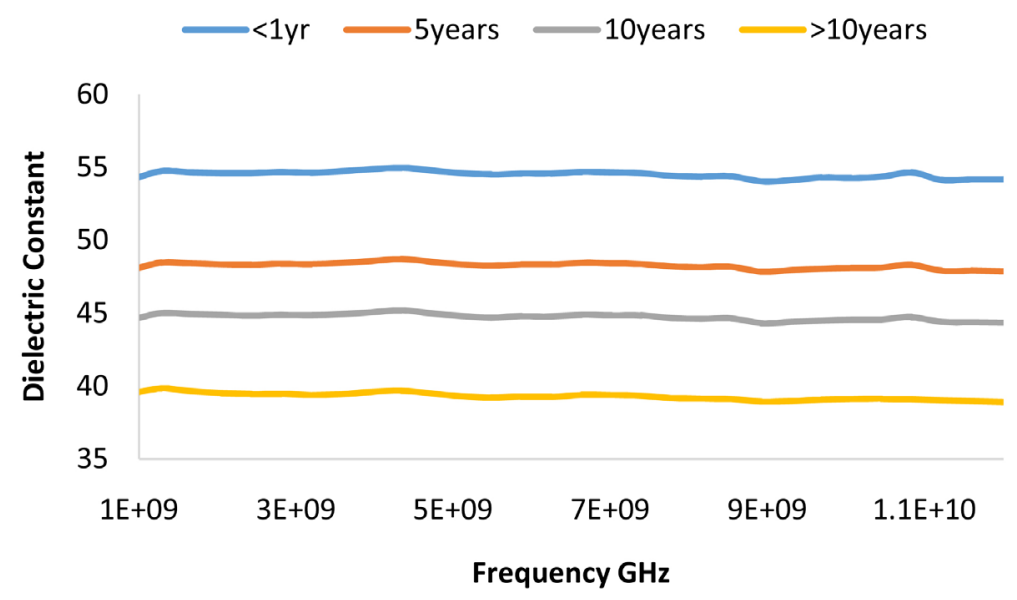

Figure 4. Variations in dielectric constant for all tissues.
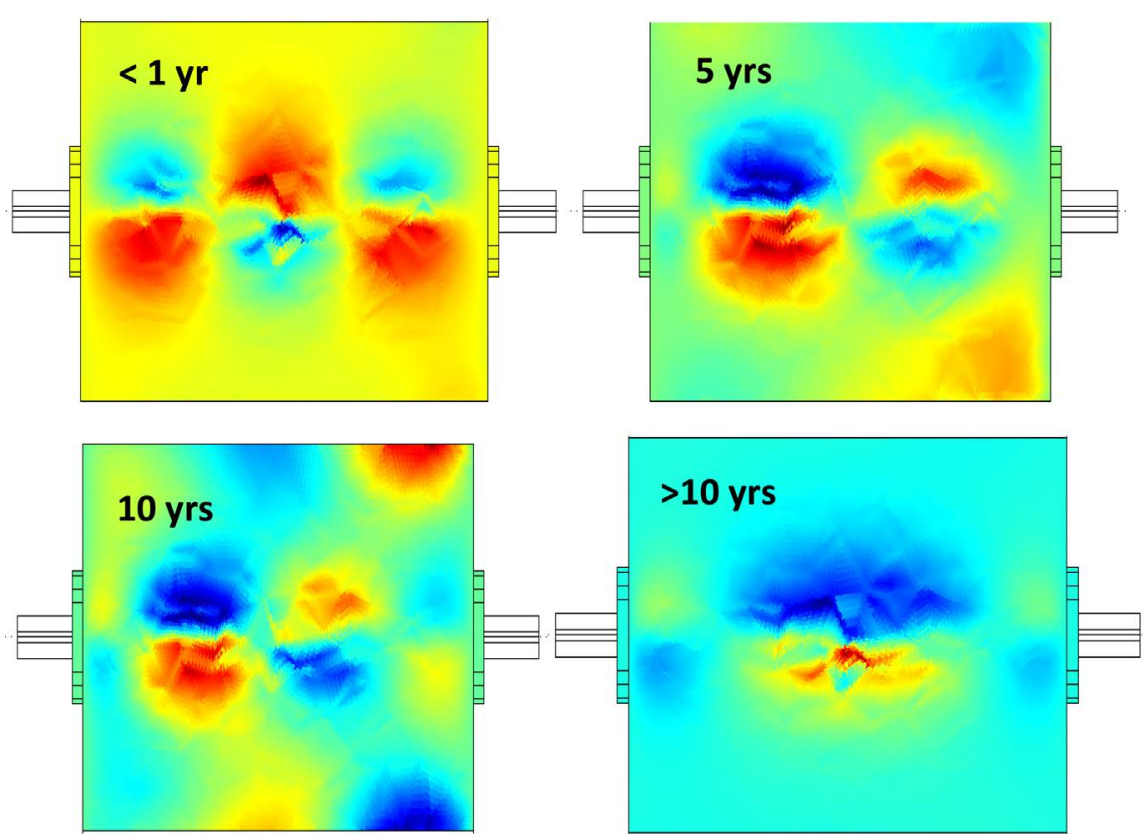

Figure 5. Variation in radiation scattering for different bovine brain tissues.

field within the simulated brain tissue. The blue represent area not affected by radiation while the red color stands for areas affected by radiation (hot spot). 
Observation and analysis on the imaging shows that there is high amount of radiation for the less than 1 year tissue.

Further observations shows that the intensity of the radiation decreased as dielectric constant decreases. As expected higher permittivity gives rise to higher absorption of electromagnetic wave through a sample. Hence, the increase in radiation intensity as shown in the simulation is in complete agreement with the permittivity result obtained for the different bovine tissues. The result is also evident in Figure 6 where the highest absorption at $2.4 \mathrm{GHz}$ is for the less than 1 year old tissue. The results confirmed that radiation absorption distribution in the brain tissue is highly dependent on permittivity values of the tissue. The difference in the bovine brain tissue used in the simulation was to show the amount of radiation that can be absorbed by the tissue depending on age. Based on the result, it is confirmed that young bovine tissue absorb more radiation than older tissue.The human brain is embedded with Ribo Nucleic Acid (RNA) for the normal functioning of the brain [16]. Furthermore, it is believed that RNA-interference can affect both the level of pathological proteins (A $\beta$, tau protein) and the onset [17] [18], hence any alteration on the RNA can lead to major brain defects.

Generally, human and bovine brains are similar in functionalities. Recent advances have shown that all vertebrate brains share a common evolutionary origin. The bovine and human brains are architecturally the same as both brains consists globally of five parts, the Medulla, Medulla oblongata, limbic system, cerebellum and cortex. Among various possible health effects of mobile phone radiation, is the risk of inducing brain tumor leading to cancer due to radio Frequency (RF) dose from mobile phones.

\section{Conclusion}

In this paper, a step-by-step non-destructive dielectric measurement and modeling methods were used to determine the dielectric constant, radiation imaging,

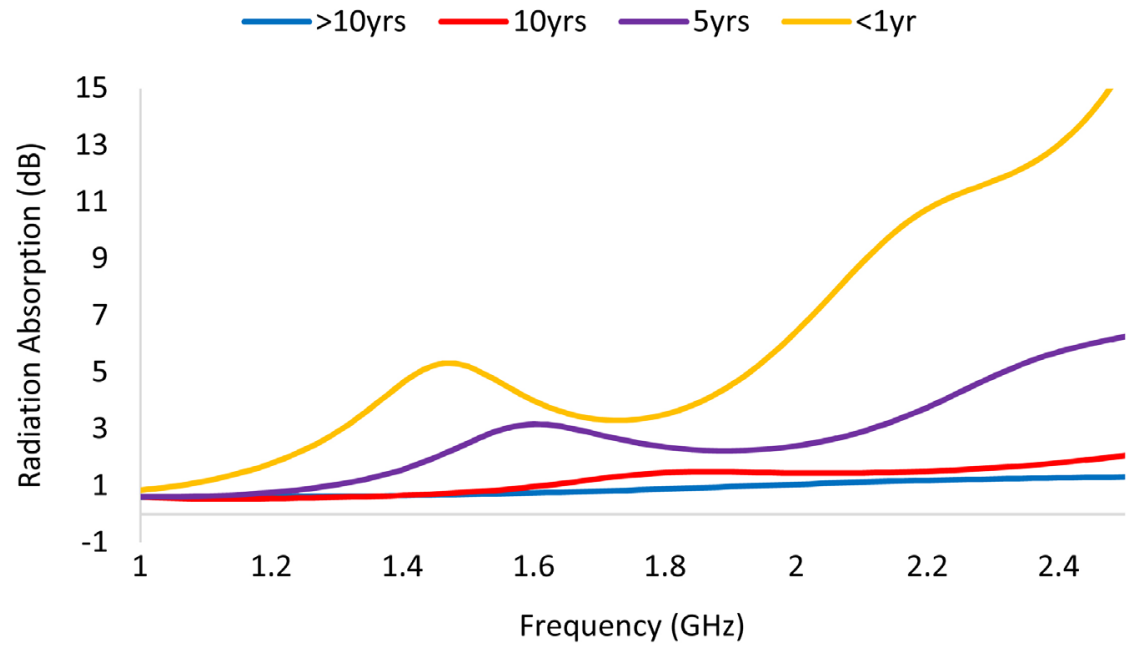

Figure 6. Radiation absorption for different bovine brain tissues at $1-2.4 \mathrm{GHz}$. 
and absorption in brain tissue. The electromagnetic characterization of bovine brain tissue as an absorber using FEM has been carried out in the frequency range of $1-4 \mathrm{GHz}$ band. The tissues were excited with a maximum power of $2500 \mathrm{~mW}$. The E.M simulation has been carried out using the measured material properties of the heterogeneous brain tissue on COMSOL Software. The maximum absorption of radiation of more than $13 \mathrm{~dB}$ was observed for the less than 1 -year-old brain tissue while the minimum absorption of about $1 \mathrm{~dB}$ was observed for the greater than 10 years old brain tissue at $2.4 \mathrm{GHz}$. It is therefore concluded that finite element method is successful in simulating radiation absorbed by brain tissue, and that radiation absorption is higher on materials with the highest permittivity value. Therefore, adolescents are prone to danger, if any, that might arise due to higher radiation absorption in brain tissues. This research method to the best of my knowledge is done for the first time in the field of electromagnetic simulation.

\section{Acknowledgements}

We thank Tertiary Education Trust (TETFund) Nigeria for the research grant and Prof. Zulkifly Abbas of the Universiti Putra Malaysia for assistance with measurements in his Laboratory.

\section{Conflicts of Interest}

The authors declare no conflicts of interest regarding the publication of this paper.

\section{References}

[1] Yakubu, A., Zulkifli, A., Nor Azowa, I. and Ahmad, F. (2015) Reduction of Electromagnetic Interference Using ZnO-PCL Nanocomposites at Microwave Frequency. Advances in Materials Science and Engineering, 2015, Article ID: 132509. https://doi.org/10.1155/2015/132509

[2] Yorgancilar, E., Dasdag, S., Akdag, M.Z., Akkus, Z., Akdag, M. and Topcu, I. (2017) Does All-Day and Long-Term Exposure to Radiofrequency Radiation Emitted from Wi-Fi Affect Hearing? Biotechnology \& Biotechnological Equipment, 31, 1204-1209. https://doi.org/10.1080/13102818.2017.1373033

[3] Morris, R.D., Morgan, L.L. and Davis, D. (2015) Children Absorb Higher Doses of Radio Frequency Electromagnetic Radiation from Mobile Phones than Adults. IEEE Access, 3, 2379-2387. https://doi.org/10.1109/ACCESS.2015.2478701

[4] Sharma, N.K., Sharma, R., Mathur, D., Sharad, S., Minhas, G., Bhatia, K., Ghosh, S.P., et al. (2018) Role of Ionizing Radiation in Neurodegenerative Diseases. Frontiers in Aging Neuroscience, 10, 134. https://doi.org/10.3389/fnagi.2018.00134

[5] Priyadarshini, S.J. and Hemanth, D.J. (2018) Investigation and Reduction Methods of Specific Absorption Rate for Biomedical Applications: A Survey. International Journal of RF and Microwave Computer-Aided Engineering, 28, e21211. https://doi.org/10.1002/mmce.21211

[6] Dasdag, S., Zulkuf, A.M., Erdal, M.E., Erdal, N., Izci, Ay.O., Ertan, Ay.M., Yilmaz, G.S., Tasdelen, B. and Yegin, K. (2015) Effects of 2.4 GHz Radiofrequency Radiation Emitted from Wi-Fi Equipment on microRNA Expression in Brain Tissue. Interna- 
tional Journal of Radiation Biology, 91, 555-561.

https://doi.org/10.3109/09553002.2015.1028599

[7] Moen, B.E., Møllerløkken, O.J., Bull, N., Oftedal, G. and Mild, K.H. (2013) Accidental Exposure to Electromagnetic Fields from the Radar of a Naval Ship: A Descriptive Study. International Maritime Health, 64, 177-182. https://doi.org/10.5603/IMH.2013.0001

[8] Foster, K.R. and Chou, C.K. (2016) Response to "Children Absorb Higher Doses of Radio Frequency Electromagnetic Radiation from Mobile Phones than Adults" and "Yes the Children Are More Exposed to Radiofrequency Energy from Mobile Telephones than Adults". IEEE Access, 4, 5322-5326.

https://doi.org/10.1109/ACCESS.2016.2601490

[9] Federal Communications Commission (FCC) (2001) OET Bulletin 65 Supplement C. Federal Communications Commission, Washington DC.

[10] Council of the European Union (CEU) (1999) Council Recommendation of 12 July 1999 on the Limitation of Exposure of the General Public to Electromagnetic Fields (0 Hz to $300 \mathrm{GHz})$. Journal of European Communities, 199, 59-70.

[11] Gultekina, D.H. and Moeller, L. (2013) NMR Imaging of Cell Phone Radiation Absorption in Brain Tissue. PNAS, 110, 58-63.

https://doi.org/10.1073/pnas.1205598109

[12] Cabot, E., Stevanovic, I., Kuster, N. and Capstick, M.H. (2019) A Numerical Assessment of the Human Body Effect in the Transmission of Wireless Microphones. Microwave and Optical Technology Letters, 61, 809-817. https://doi.org/10.1002/mop.31623

[13] Kempf, S.J., Azimzadeh, O., Michael, J., Atkinson, M.J. and Tapio, S. (2012) Long-Term Effects of Ionizing Radiation on the Brain: Cause for Concern? Radiation Environment Biophysics, 52, 5-16. https://doi.org/10.1007/s00411-012-0436-7

[14] Nguyen-Thoi, T., Phung-Van, P., Rabczuk, T., Nguyen-Xuan, H. and Le-Van, C. (2013) Free and Forced Vibration Analysis Using the n-Sided Polygonal Cell-Based Smoothed Finite Element Method (ncs-FEM). International Journal of Computational Methods, 10, Article ID: 1340008. https://doi.org/10.1142/S0219876213400082

[15] Pozar, D.M. (2012) Microwave Engineering. 4th Edition, John Wiley and Sons Inc., Hoboken.

[16] Jonkhout, N., Tran, J., Smith, M.A., Schonrock, N., Mattick, J.S. and Novoa, E.M. (2017) The RNA Modification Landscape in Human Disease. $R N A, 23,1754-1769$. https://doi.org/10.1261/rna.063503.117

[17] Dorszewska, J., Prendecki, M., Oczkowska, A., Dezor, M. and Kozubski, W. (2016) Molecular Basis of Familial and Sporadic Alzheimer's Disease. Current Alzheimer Research, 13, 952-963. https://doi.org/10.2174/1567205013666160314150501

[18] Ballard, D.H. (2015) Brain Computation as Hierarchical Abstraction. MIT Press, Cambridge. https://doi.org/10.7551/mitpress/9780262028615.001.0001 